\title{
Assessment of the possibility of using nanomaterials as fuel additives in combustion engines
}

\section{ARTICLE INFO}

Received: 26 September 2021

Revised: 30 October 2021

Accepted: 9 November 2021

Available online: 5 December 2021
Nanomaterials are a new group that has quickly found a wide range of applications in medicine, cosmetology, the food, weapons or automotive industry. They are also used as a fuel additive. This paper reviews the literature and assesses the current state of knowledge regarding the use of nanoparticles in automotive engine fuels. The results obtained so far are presented and further research directions in this field are identified.

Key words: internal combustion engines, diesel fuel, fuel additives, emission of pollutants, engine operation

This is an open access article under the CC BY license (http://creativecommons.org/licenses/BY/4.0/)

\section{Introduction}

Road transport is the most prevalent mode of transportation. Internal combustion engines are invariably the most popular form of propulsion and diesel is the dominant fuel. This results in high environmental pollution, mainly due to emission of harmful substances such as carbon monoxide, particulate matter, unsaturated hydrocarbons and nitrogen oxides into the atmosphere, which contribute to the formation of smog. The pollution produced poses a threat not only to the ecosystem, but also to human health and life. In order to reduce the problem resulting from the use of internal combustion engines, a number of researches are being conducted in a variety of areas related to efficient combustion, fuel cleaning technology, catalytic technology, particulate filters, and the use of alternative fuels. Strict regulations related to the limitation of pollutant emissions force both scientists and entrepreneurs to look for alternatives to fossil fuels (e.g. biodiesel, dimethyl ether, alcohols, natural gas, dimethyl carbonate or hydrogen [9]). In addition, additives are used to reduce harmful emissions. These include calcium-, phosphorus-, silicate-, alcohol-based products, tertiary additives like nitromethane, nitroethane, methyl ester, nano additives $[4,7]$. These are very rapidly growing areas. In this article, the authors have undertaken to analyze and evaluate current developments in the area related to the use of fuel additives, limiting the review study conducted to nanomaterials. The aim of the paper is to present the possibility of their application as fuel additives, to show potential benefits resulting from their use and to justify the necessity of conducting further research, especially in view of their so far marginal application in the automotive industry, estimated (in relation to other branches of industry) at about $1 \%$ [13]. The authors hypothesized (research hypothesis) that the use of nanomaterials as fuel additives is an important element in the development of the automotive industry in line with the sustainable transport paradigm because it contributes to the reduction of harmful emissions to the atmosphere through chemical mechanisms and the presence of functional groups capable of improving fuel combustion quality.

\section{Characteristics of nanomaterials}

Nanomaterials are a group of materials both naturally occurring and synthesized, of any dimension, but having structure at the nanoscale i.e. 1 to $100 \mathrm{~nm}$ [3]. Nanomaterials are characterized by very good mechanical, electrical, optical and thermal properties. Nanomaterials find wide applications in automotive industry, including production of paints, coatings, lubricants, materials for electrical and electronic devices, sensors, etc. They are also produced as a lightweight material with high strength as well as corrosion and heat resistance, used in structural components [1]. However, the authors would like to pay special attention to their use as a fuel additive. According to available research in this area, nanoparticles are effective in reducing emissions and improving engine performance [17]. The use of additives can change parameters such as density, volatility or sulfur content [17]. In addition, it affects ignition time, ignition delay, friction, and emissions of harmful pollutants such as nitrogen oxides, carbon monoxide, carbon dioxide, unburned hydrocarbons, smoke.

The most popular nanomaterials include cerium oxide, carbon nanotubes, aluminum oxide, titanium oxide, graphene oxide, aluminum oxide, iron oxide, copper oxide, and zinc oxide. Their chemical and physical properties are presented later in this article.

\subsection{Physical and chemical properties of nanomaterials}

\section{Carbon nanotubes}

Carbon nanotubes are allotropic varieties of carbon, long, thin, and cylindrical in shape, about $1-3 \mathrm{~nm}$ in diameter and hundreds to thousands of nanometers in length [4, 16]. In terms of structure, carbon nanotubes can be divided into: Single-Wall Carbon Nanotubes (SWCNT) and Multiwalled Carbon Nanotubes (MWCNT). Single-wall carbon nanotubes consist of a single graphene sheet with a tubelike structure, while multi-walled ones consist of multiple graphene sheets $[2,16]$.

Single-wall nanotubes range from 0.4 to $10 \mathrm{~nm}$ in diameter while multi-walled ones from 10 to $100 \mathrm{~nm}$ [2]. Carbon nanotubes are characterized by their ability to form oxi- 
dized forms of CNTs by the action of acids such as nitric, sulfuric, or potassium manganate Oxidized carbon nanotubes dissolve better in water by becoming more polar [21]. Comparing carbon nanotubes to conventional powdered or granular activated carbon, they feature a large active surface area to volume ratio, thus showing a higher potential to remove heavy metals from water, while conventional activated carbon is characterized by a smaller active surface area and activation energy [16].


Fig. 1. Shows a) single-wall carbon nanotubes b) multi-walled carbon nanotubes [24]

\section{Metal oxides and non-metal oxides}

Metal oxide nanoparticles include mainly $\mathrm{TiO}_{2}, \mathrm{Fe}_{3} \mathrm{O}_{4}$, $\mathrm{SiO}_{2}, \mathrm{Al}_{2} \mathrm{O}_{3}$. They are of interest to a wide range of researchers due to their versatile properties, which include environmental friendliness, non-toxicity, high electrical and mechanical conductivity, large specific surface area, ease of synthesis and low manufacturing cost. They find application mainly in sorption or composite formation. Metal oxide composites with porous structures are gaining popularity because they exhibit, due to combining different material properties, higher yield compared to conventional metal oxides [20].

\section{Iron nanoxide}

Iron oxide-based nanomaterials exhibit great potential for eliminating pollutants due to their superparamagnetism. They are characterized by low production costs, are easy to obtain, have a large surface-to-volume ratio, and are harmless. Iron nanoxides find vast application in adsorption due to their high SSA (specific surface area) (30-100 $\mathrm{gm}^{-1}$ ) [22]. They feature reactive surface sites and functional groups, which contributes to the effective adsorption of contaminants.

Iron oxide-based nanoparticles come in various forms, e.g.: nano ovals, nano rings, nano strips and graphene-based complexes for the elimination of heavy metals. In nature, iron oxides occur in several forms such as hematite $\left(\alpha-\mathrm{Fe}_{2} \mathrm{O}_{3}\right)$, magnetite $\left(\mathrm{Fe}_{3} \mathrm{O}_{4}\right)$, maghemite $\left(\gamma-\mathrm{Fe}_{2} \mathrm{O}_{3}\right)$, goethite $(\alpha-\mathrm{FeOOH})$, lepidocrocite $(\gamma-\mathrm{FeOOH})$, and hydrous ferric oxide (HFO).) However, hematite, magnetite, and maghemite have found the greatest use in water treatment because they exhibit extraordinary surface charge properties and redox activity, as well as polymorphism that includes a temperature-induced phase transition and unique magnetism [19]. Hematite is a relatively inexpensive adsorbent and is the most stable iron oxide. It is used for adsorption of organic pollutants and heavy metals [19]. Magnetite also has a strong affinity for ions such as $\mathrm{Pb}(\mathrm{II}), \mathrm{Cu}(\mathrm{II})$, $\mathrm{Cd}(\mathrm{II})$. Magnetite exhibits a reducing ability that contributes to adsorption. According to [19], $\gamma-\mathrm{Fe}_{2} \mathrm{O}_{3}$ reduces
$\mathrm{Cr}$ (IV) to $\mathrm{Cr}$ (III) and causes its immobilization on the surface. It is also an effective adsorbent of $\mathrm{As}(\mathrm{V})$ because it shows high affinity between $\mathrm{Fe}^{3+}$ and $\mathrm{As}^{5+}$ [19].

Iron oxides: $\mathrm{Fe}_{3} \mathrm{O}_{4}$ and $\gamma-\mathrm{Fe}_{2} \mathrm{O}_{3}$ are characterized by strong magnetic properties, which depend on the particle size, composition and shape - when the particle size is 15 $\mathrm{nm}$ or $40 \mathrm{~nm}$, they can already obtain supermagnetic properties [19], i.e. that they are attracted by a magnetic field, but do not retain magnetic properties after the field is removed.

\section{Aluminum oxide}

They are characterized by low manufacturing cost, significant toxicity, large specific surface area, large pore volume. The following forms can be distinguished: hexagonal, orthorhombic, monoclinic, tetragonal and cubic, core. According to [19], aluminum oxide exhibits a strong affinity for adsorption of arsenic and fluorine. Mesoporous $\gamma-\mathrm{Al}_{2} \mathrm{O}_{3}$ show the best adsorption properties for heavy metal removal.

\section{Titanium dioxide}

Nano titanium dioxide has a dual application: adsorption and photocatalysis of organic compounds. Photocatalysis does not work in the case of high concentrations of organic pollutants due to poor light transmission. On the other hand, titanium dioxide-based nanomaterials show high adsorption capacity of heavy metal ions like lead, cadmium, tin, nickel and copper. According to [6], there are several mechanisms for adsorption of contaminants on titanium dioxide. The Ti(IV) ion can act as a Lewis acid due to the uncompensated positive charge that coordinates molecules with a free pair of electrons. In contrast, $\mathrm{O}_{2}{ }^{-}$is a Lewis base and adsorbs acidic molecules and cations. Other interactions between titanium dioxide and impurities include hydrogen bonding and electrostatic interaction.

\section{Graphene oxide}

The oxidized form of graphene is graphene oxide (GO), which is formed by oxidation and exfoliation. Graphene oxide contains an oxygen-containing group. It can be a: phenolic, carboxyl, hydroxyl or epoxy group.

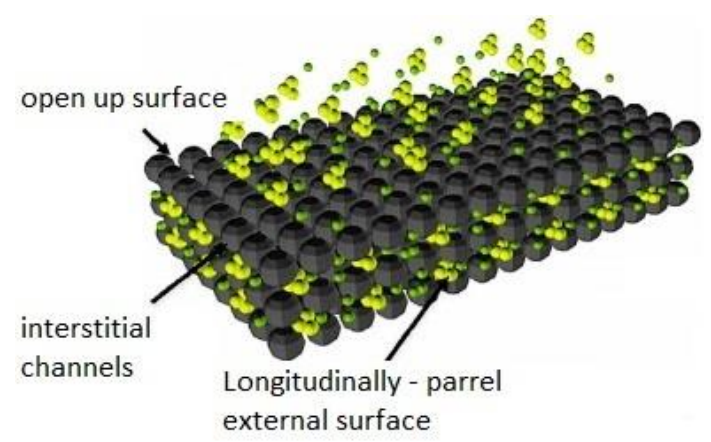

Fig. 2. Structure and adsorption site of graphene sheets [2]

Consequently, the surface has a negative charge and positive ions can be attracted by electrostatic interaction. The adsorption efficiency can be improved by introducing additional oxygen-containing groups from polymer particles, metal oxides or hydroxides. These can include caboxymethyl cellulose, ethylenediaminetetraacetic acid 
(EDTA), $\mathrm{ZnO}$, acetylacetone and $\mathrm{TiO}_{2}$. The reaction occurring between ions and groups depends on the $\mathrm{pH}$ value. As $\mathrm{pH}$ increases, the oxygen-containing groups are deprotonated and as a consequence the adsorbent surface is more negatively charged - the attraction of positively charged cations increases. However, with a decrease in $\mathrm{pH}$, protonation and the reverse phenomenon occurs [22]. In addition, $\mathrm{pH}$ also affects the very form of heavy metal cations that can hydrolyze to hydroperoxides. At high $\mathrm{pH}$, precipitation of cations may occur or negatively charged hydroxides will form, which will electrostatically repel from the adsorbent.

\section{Nanoparticles as fuel additives}

\subsection{Cerium oxide}

According to [11], cerium oxide has the ability to catalyze combustion reactions by passing oxygen ions from its lattice structure. The addition of cerium oxide to the fuel aids in the breakdown of unburned hydrocarbons and their residues, thereby reducing toxic vapor emissions while consuming less fuel. The addition of cerium oxide helps to reduce the weight of the fuel in the combustion chamber, which limits the formation of nitrogen oxides and makes ignition reactions more efficient. In [23], tests consisting in adding cerium nanoxide at $100 \mathrm{mg} / \mathrm{l}$ to diesel fuel and checking its effect on the performance of a four-stroke diesel engine were carried out. The nanopowders were 25 $\mathrm{nm}\left(\mathrm{Ce}_{25}\right)$ and $50 \mathrm{~nm}\left(\mathrm{Ce}_{50}\right)$ in size. The parameters of nano additives used in the study are summarized in Table 1.

Table 1. Physical characteristics of the materials used [23]

\begin{tabular}{|l|c|c|c|}
\hline Type & $\begin{array}{c}\text { Bulk density } \\
{\left[\mathrm{g} / \mathrm{cm}^{3}\right]}\end{array}$ & $\begin{array}{c}\text { Specific surface } \\
\text { area }\left[\mathrm{m}^{2} / \mathrm{g}\right]\end{array}$ & Size $[\mathrm{mm}]$ \\
\hline $\mathrm{Ce}_{25}$ & 0.53 & $30-50$ & $\operatorname{Max} 25$ \\
\hline $\mathrm{Ce}_{50}$ & 0.53 & $30-50$ & Max 50 \\
\hline
\end{tabular}

$\mathrm{Ce}_{25}, \mathrm{Ce}_{50}$ were mixed with standard diesel at $40 \mathrm{ppm}$ and then ultrasonically vibrated for two hours to obtain a homogeneous blend. After 24 hours, the mixtures were pumped into a fuel tank at the test stand. Diesel fuel produced by Coryton Advanced Fuels was used as a reference.

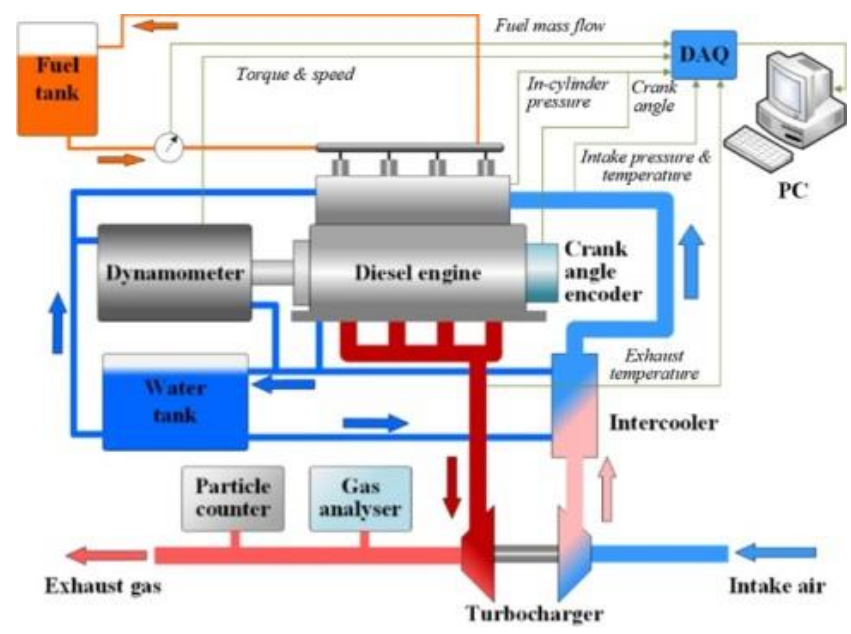

Fig. 3. Measuring station [23]

The study was conducted using a Cummins ISBN fourstroke diesel engine. Fuel was compressed through a com- mon rail and injected through four injector ports. Flow rate was measured with a Coriolis flowmeter, while pressure was controlled in the third cylinder using an AVL QC34C pressure transducer. The gas analyzer detected carbon monoxide, nitrogen oxides, and unburned hydrocarbons.

Fuel was pumped into the fuel tank. The engine was run for $20 \mathrm{~min}$ at $1,600 \mathrm{rpm}$ and $25 \%$ load to consume all the fuel in the system and warm up the engine. After the experiment was completed with the test fuel, it was drained and the lubricating oil was renewed. The next day, all steps were repeated using a new batch of test fuel. The experimental conditions lasted for two minutes. Pressure, flow rate, and gaseous emissions were recorded. Based on the research conducted, the following conclusions were made in each area [23].

\section{Fuel consumption}

The additives used have no significant effect on the diesel engine's fuel consumption. The cerium nanoxide alters only the physicochemical properties resulting from the atomization and reaction rates of the composition and fuel products.

\section{CO emissions}

$\mathrm{CO}$ emissions are dependent on engine speeds. Emissions increase with increasing engine load because the airfuel ratio decreases at high load, causing incomplete combustion when oxygen is in short supply.

At certain threshold values, emissions fall and then rise sharply. This is because at high speeds the combustion time is shorter causing more incomplete combustion which accelerates $\mathrm{CO}$ production. At high loads, $\mathrm{CO}$ emissions are reduced compared to regular diesel.

\section{NO $_{\mathrm{x}}$ emissions}

The addition of $\mathrm{CeO}_{2}$ nanopowders contributes to the reduction of $\mathrm{NO}_{\mathrm{x}}$. The cerium oxide assumes the function of a catalyst that promotes oxidation of unburned fuel compositions. $\mathrm{Ce}_{2} \mathrm{O}_{3}$ contributes to the deoxidation of oxidation products. $\mathrm{NO}_{\mathrm{x}}$ oxides are reduced using the equation [23]:

$$
\mathrm{Ce}_{2} \mathrm{O}_{3}+2 \mathrm{NO} \rightarrow 2 \mathrm{CeO}_{2}+\frac{1}{2} \mathrm{~N}_{2}
$$

$\mathrm{Ce}_{25}$ is characterized by higher specific $\mathrm{NO}_{\mathrm{x}}$ emission than $\mathrm{Ce}_{50}$, which is a consequence of the different sizes of $\mathrm{CeO}_{2}$ nanopowders. As [23] studies have shown, fuels with nano additives produce lower emissions compared to regular diesel.

\section{Emissions of unburned hydrocarbons}

Emissions of unburned fuel compositions is favored by incomplete combustion, atomization, as well as high temperature and presence of oxidants. As [23] studies have shown, emissions decrease with increasing load at all speeds. Unburned fuels easily oxidize and form soot - socalled particulates - due to carbonization and dehydrogenation.

The nano additive reduces unburned hydrocarbon emissions, but only at certain speeds in the 1,490-1,855 rpm range. Hydrocarbon emissions decrease at 2,200 rpm as they then spend less time in the combustion chamber where the reaction is limited. 


\section{PM emissions}

The addition of nano-oxide contributes to lower emissions than for pure diesel, regardless of changing load and speed. This is because cerium oxide oxidizes particulate matter and simultaneously consumes unburned components (particles, elements) of fuels before they can be converted to particulate matter by carbonization and dehydrogenation reactions. However, $\mathrm{Ce}_{25}$ particles are characterized by lower specific emissions than $\mathrm{Ce}_{50}$ because the small size particles can more easily aggregate unburned fuel particles.
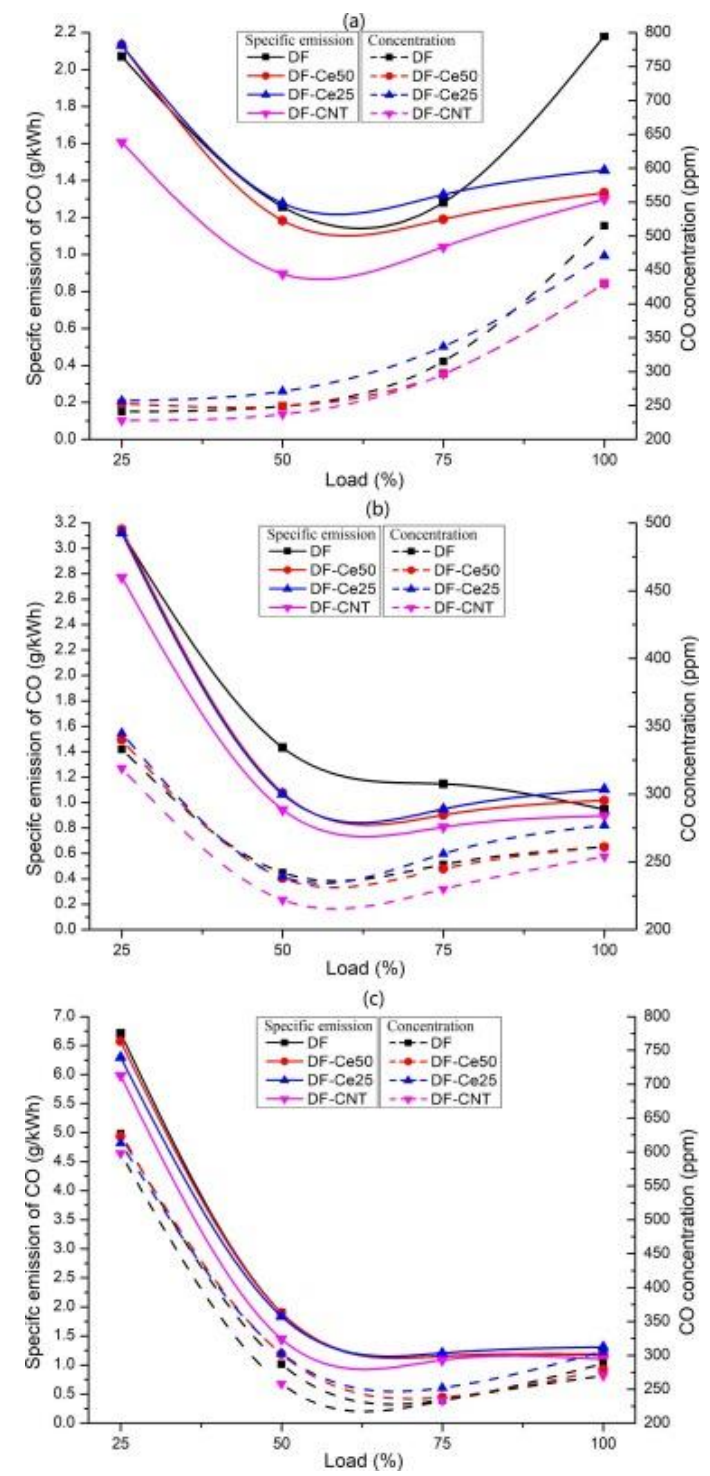

Fig. 4. CO emission from the tested fuels at engine speeds of $1490 \mathrm{rpm}$ (a), 1855 (b), and $2200 \mathrm{rpm}$ (c) [24]

\subsection{Carbon nanotubes}

A group of particular importance are carbon nanotubes (CNTs), which due to their high magnetic, electrical, optical and thermal conductivity exhibit a significant potential for use as fuel additives to improve performance and reduce emissions of harmful substances. The research conducted in [14] focused on studying the effect of adding multi-walled carbon nanotubes (MWCNTs-COOH) to biodiesel as an admixture to standard diesel fuel. The test was conducted in one cylinder of the engine.

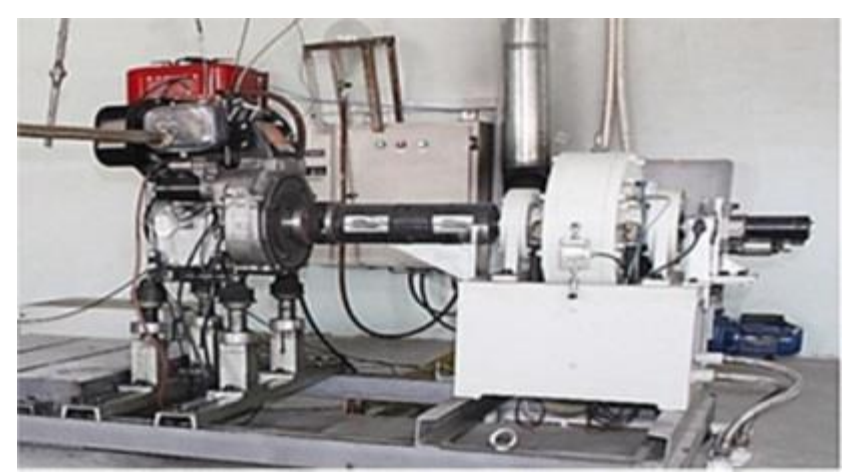

Fig. 5. Engine and dynamometer [14]

As reported by [14] MWCNTs-COOH have amide groups that are able to react with many reagents. Multiwalled carbon nanotubes (MWCNTs-COOH) were mixed at 30,60, $90 \mathrm{ppm}$ with a solution containing $95 \%$ diesel fuel and 5\% biodiesel (B5). The fuel was mixed for $30 \mathrm{~min}$ in an ultrasonic device to obtain a homogeneous blend.

As reported in [14], a DICOM 50.115/5 model diesel engine was used. An eddy current test bed with remote control (MPA-40 model) was used to measure torque, while an emission tester was used to measure exhaust gas. Physiochemical parameters like dynamic and kinematic viscosity and flash point were determined after blend (fuel) preparation. The tests were conducted for three speeds of 1,800 , 2,100 and 2,400 rpm at full engine load. In addition, power, torque, temperature, pressure, and ambient humidity were recorded during each test. The running time of the engine was $10 \mathrm{~min}$. The following results were obtained [14].

\section{Technical performance of the engine}

Adding multi-walled carbon nanotubes to the diesel/biodiesel mixture increases torque and braking power, which is defined as the rate of work done by the engine. The fuel mixture of B5 and MWCNTs-COOH at 1,800, 2,100 and $2,400 \mathrm{rpm}$ results in $20.58 \%, 20 \%$ and $7.59 \%$ increase in power, respectively. The increase in power and torque is explained by improved combustion quality inside the cylinder (combustion is complete). The functionalized nanotubes have sufficient oxygen amount which contributes to complete combustion. Another reason for the increase in power and torque is the catalytic activity of the nanoparticles, which results in a reduction in ignition delay and fuel combustion time. In addition, MWCNTs-COOHs enhance heat transfer as a result of increase in the surface-to-volume ratio. Moreover, the addition of nanotubes reduces the viscosity of the fuel, resulting in increased power. The specific fuel consumption increases due to the addition of MWCNTs-COOH which is explained by faster combustion, higher heat release and lower combustion delay.

\section{Environmental parameters}

\section{Carbon monoxide ( $\mathrm{CO})$}

Carbon monoxide is produced by semi-combustion, i.e. with a limited amount of oxygen. Carbon monoxide formation in the combustion process can also be caused by low flame temperatures. Oxygen groups, present in multiwalled carbon nanotubes, help increase the oxygen present in combustion, resulting in improved combustion and lower 
emissions of environmentally harmful carbon monoxide. Tests conducted in [14] showed that there was a reduction in $\mathrm{CO}$ emissions at all speeds.

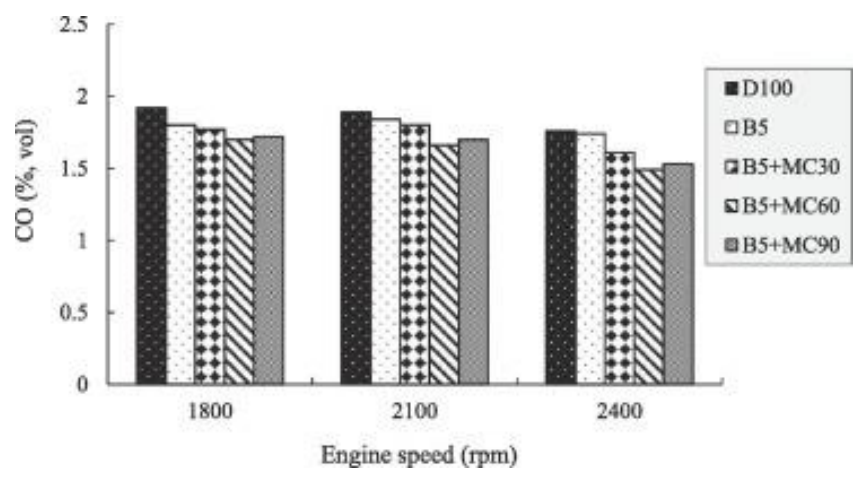

Fig. 6. Effect of the additive on CO emission [14]

Compared to conventional diesel, the blend of B5 fuel and carbon nanotube additive resulted in reductions of $11.45 \%, 10.05 \%$ and $15.34 \%$ at $1,800,2,100$ and 2,400 rpm, respectively.

\section{Carbon dioxide $\left(\mathrm{CO}_{2}\right)$}

Providing additional oxygen from MWCNTs-COOH additives and converting semi-combustion to complete combustion produces more carbon dioxide on combustion. In a study published by [14], the increase in emissions produced by carbon nanotube fuel blend at 1,800 and 2,100 rpm amounted to $14.28 \%$ and $26.92 \%$, respectively.

\section{Unburned hydrocarbons $\mathrm{UHC}$}

Unburned hydrocarbons are produced by low temperature combustion and dilution of the fuel mixture. Using carbon nanotubes, the reduction in UHC formation at 1,800 and $2,100 \mathrm{rpm}$ for diesel amounted to $18.91 \%, 20.58 \%$, and $13.04 \%$ and $15.55 \%$, respectively, compared to B5 fuel [14].

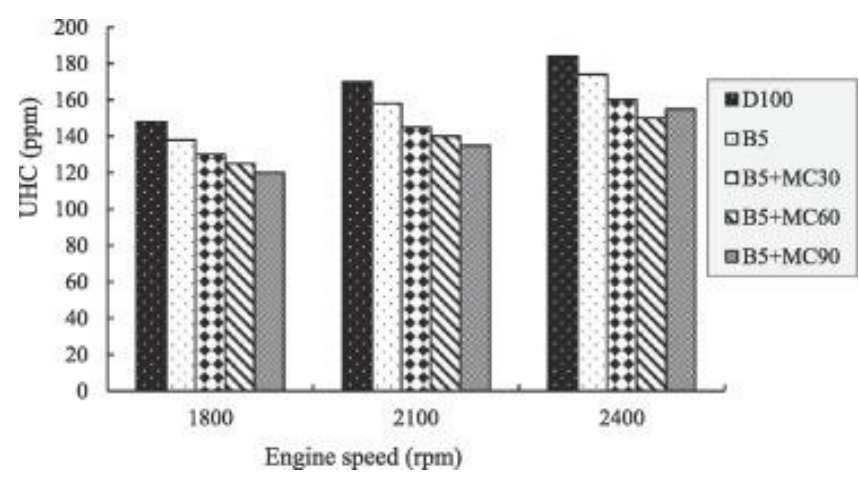

Fig. 7. Effect of the additive on UHC emission [14]

The decrease in emissions is explained similarly to $\mathrm{CO}$ and $\mathrm{CO}_{2}$ by an improvement in combustion quality due to the supply of oxygen. In addition, the use of carbon nanotubes improved atomization and fuel distribution in the chamber by oxidizing hydrocarbons and carbon monoxide.

\section{Nitrogen oxide $\mathrm{NO}$}

Combustion temperature is responsible for nitrogen oxide emissions. The higher the temperature, the higher the nitrogen oxide emissions. The combustion temperature depends on the cetane number and the quality of the fuel. According to [14], the addition of carbon nanotubes to fuel increases NO emissions by $0.74 \%$ and $0.24 \%$ on average compared to diesel and diesel/biodiesel blend.

\section{Aluminum oxide}

Aluminum nanoxide has a larger surface area compared to the bulk. Nano $\mathrm{Al}_{2} \mathrm{O}_{3}$ has a small size so it can be mixed in biodiesels and used in compression ignition engines $\mathrm{NO}$ emission problems and performance degradation can be reduced by using some nano additives. A fuel blend of $80 \%$ diesel and $20 \%$ biodiesel, $100 \mathrm{mg} / \mathrm{ml}$ alumina nanoparticles and isopropanol - as a surfactant - which prevented phase separation were used in a study conducted in [12]. The blend was ultrasonically treated to reduce particle agglomeration.

\section{Thermal efficiency of braking:}

The addition of aluminum nanoxide to diesel fuel increased the viscosity, which contributed to a decrease in fuel atomization and combustion rate.

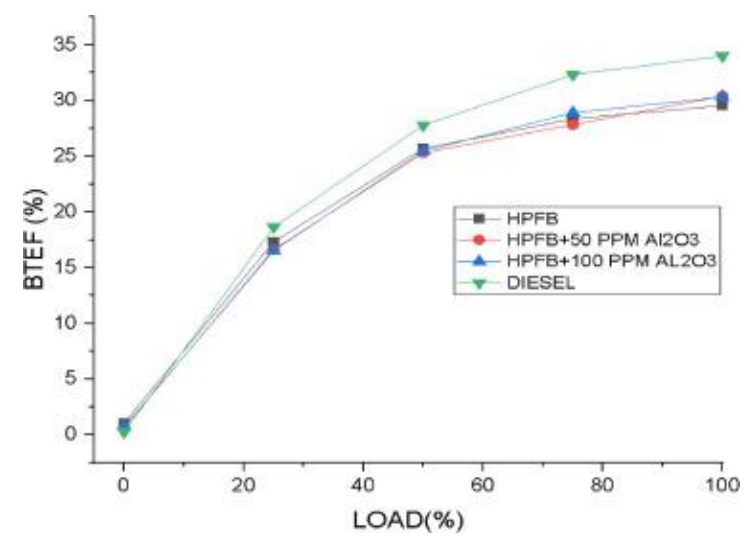

Fig. 8. Effect of the additive on thermal efficiency of braking [12]

There are slight differences in thermal efficiency between the pure diesel tested and the diesel with nano additive. However, the addition of aluminum oxide causes a slight decrease in thermal braking efficiency.

\section{Exhaust temperature}

At low engine loads, the exhausts temperatures of both fuels were similar. In contrast, the temperature of both exhausts increases at higher loads. This is explained by the fact that complete combustion occurs at low load. As the viscosity of the fluid increases, the load increases, resulting in a higher exhaust temperature.

According to the relation presented in [12], the addition of aluminum oxide slightly contributes to the increase in exhaust temperature.

\section{Carbon monoxide emissions}

As reported by $[12,15]$ as the workload of the diesel engine increases, $\mathrm{CO}$ emissions increase, but the addition of aluminum oxide causes the increase in emissions to be less.

\section{Carbon dioxide emissions}

The use of biodiesel as a diesel additive increases $\mathrm{CO}_{2}$ emissions. In tests conducted in [12], it was shown that the use of aluminum oxide nano-additive in combination with bio- 
diesel reduces carbon dioxide emissions, which is, however, still higher than in the case of pure diesel at all engine loads.

\section{Hydrocarbon emissions}

Studies in $[12,15]$ have shown that at all engine loads, nano-oxide results in lower hydrocarbon emissions (similar to carbon dioxide emissions) but hydrocarbon emissions are the lowest in the case of pure diesel.

\section{$N O_{x}$ emissions}

The results obtained in [12] show that at engine loads of $0 \%, 25 \%$ and $100 \%$, the highest emissions are recorded for pure diesel compared to high performance fuel and high performance fuel with 50 and 100 ppm aluminum oxide additives. A mixture with a concentration of 100 ppm oxide gave the lowest toxic $\mathrm{NO}_{\mathrm{x}}$ emissions.

\section{Titanium oxide}

Titanium oxide nanoparticles have found application primarily as a biodiesel additive. They are able to improve engine performance and reduce harmful emissions. The tests conducted in [8] used a Kirloskar TV1 four-stroke, single-cylinder, vertical, water-cooled engine. The test fuels were fed to the engine under varying load conditions controlled by a dynamometer. Fuel consumption was recorded every 10 seconds. Smoke, hydrocarbon emissions, $\mathrm{NO}_{\mathrm{x}}$, $\mathrm{CO}, \mathrm{CO}_{2}$ were characterized. Brake thermal efficiency, volumetric efficiency, exhaust temperature and specific fuel consumption were also tested.

\section{Specific fuel consumption}

Defined as the total amount of fuel burned by an engine per unit of mechanical work or energy, decreases with engine load [8]. The addition of titanium nanoxide results in reduced fuel consumption compared to biodiesel. Both in [8] and [18] studies, fuel consumption decreased with the increase in $\mathrm{TiO}_{2}$ concentration. However, a nano-additive concentration above $250 \mathrm{ppm}$ is not recommended as the engine will not run satisfactorily.

\section{Thermal efficiency of the brake}

It is the ratio between the braking (output) power and the output heat. In other words, the ability to convert an input such as heat into mechanical energy. The addition of titanium oxide at engine efficiencies above $>60 \%$ results in better efficiency than for regular biodiesel [8].

\section{Carbon monoxide emissions}

The addition of $\mathrm{TiO}_{2}$ nanoparticles reduces emissions compared to diesel [18]. This can be explained by the higher activation energy of titanium dioxide, which, by acting as an antioxidant, causes complete combustion.

\section{Carbon dioxide emissions}

In [8] tests, carbon dioxide emissions for pure biodiesel were the lowest. However, the higher the concentration of titanium oxide in the blend, the lower the emission. At 200 ppm, emissions were already at levels comparable to pure biodiesel.

\section{Unburned hydrocarbons}

Unburned hydrocarbons show the extent to which the fuel has not been burned properly. These compounds are the major smog contributors in large cities. In both $[8,18]$ tests, hydrocarbon emissions were lower in case of titanium oxide fuels. However, tests in [18] have additionally shown that a blend with biodiesel alone produces lower emissions than pure diesel. $\mathrm{TiO}_{2}$ nanoparticles contribute to complete combustion resulting in lower emissions of environmentally troublesome hydrocarbons. According to [18], as $\mathrm{TiO}_{2}$ concentration increases, hydrocarbon and carbon monoxide emissions increase. This is explained by increased viscosity, lower heating value and flash point.

\section{Nitrogen oxides $\left(\mathrm{NO}_{x}\right)$}

Observing the results obtained in $[8,18]$ one can see an increase in nitrogen oxide emissions in case of both pure and blended with titanium oxide biodiesel, compared to diesel. The increase in $\mathrm{NO}_{\mathrm{x}}$ emissions may be a consequence of increased combustion rates, resulting in higher temperatures and oxygen availability for oxidation. However, tests [8] showed that at a concentration of $200 \mathrm{ppm}$ $\mathrm{TiO}_{2}, \mathrm{NO}_{\mathrm{x}}$ emissions are lower compared to biodiesel.

\section{Graphene oxide}

Recently, monolayer graphene has gained great popularity. It is non-toxic, features a high surface-to-volume ratio, thermal dissociation and chemical volume.

Graphene has atoms in $\mathrm{sp}^{2}$ hybridization state and has two-dimensional flat sheets of carbon atoms. Graphene oxide is graphene with oxygen functional groups in its structure. These groups may include: hydroxyl $(-\mathrm{OH})$, epoxy $(-\mathrm{C}-\mathrm{O}-\mathrm{C})$, carbonyl $(\mathrm{C}=\mathrm{O})$ and carboxyl $(\mathrm{COOH})$ groups [5].

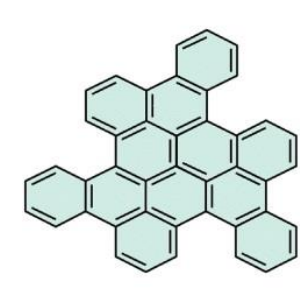

(a) Graphene

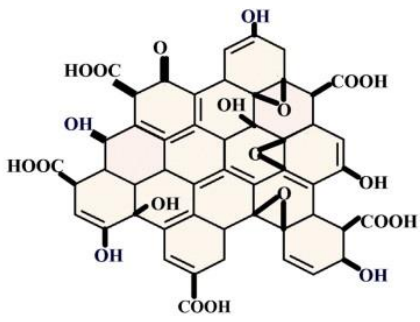

(b) Graphene oxide
Fig. 9. Chemical structure of graphene and graphene oxide [5]

In the test conducted in [5], a blend of diesel fuel and graphene oxide with different concentrations, i.e: $20,40,60$ ppm, was used to check the effect of GO additive. The fuel blend was prepared in two stages. First, 1 liter of fuel was mixed with nano additives using a magnetic stirrer at 900 rpm for $20 \mathrm{~min}$. In the second step, the blend was placed in an ultrasonic probe to improve stability. A two-cylinder, four-stroke turbocharged diesel engine was used for the test. The engine was controlled by an electronic control module. The study was conducted with a triple injection sequence. Analytical results obtained

\section{Friction characteristics}

According to [5], fuel composition and the presence of additives affect friction - mainly sliding friction - in the fuel injector. The presence of graphene oxide results in reduced friction in all three fuels tested. GO nanoparticles are highly permeable, and when mixed with fuel, they reduce sliding friction between fuel particles and the injector surface. 


\section{Ignition delay}

The ignition delay is strongly dependent on the cetane number. The presence of GO nanoparticle affected the ignition delay. The greatest reduction was observed at a concentration of $40 \mathrm{ppm}$. Graphene oxide has functional groups that are able to carry oxygen and facilitate fuel combustion.

\section{Combustion time}

The use of the nano additive reduced the combustion time. This is explained by the fact that GO has catalytic activity, where a large surface area increases the rate of combustion. According to [5] the most effective concentration is $40 \mathrm{ppm}$ (not $60 \mathrm{ppm}$ ). The GO concentration in the fuel must not be too high because agglomeration of individual particles can occur due to Van der Waals forces. Particle agglomeration can reduce the total surface area, resulting in a weakened performance of the nano additive.

\section{Mass fraction burn}

As [5] test results show, the presence of GO contributes to faster fuel burn. The faster combustion rate is explained by the fact that the instantaneous fuel-air reaction zone is charged by the presence of oxygen in the functional groups.

\section{Temperature in cylinder}

For pure diesel, a temperature decrease of $31^{\circ} \mathrm{C}$ was observed at a concentration of $40 \mathrm{ppm}$ GO, while a temperature increase of more than $20^{\circ} \mathrm{C}$ was observed for the diesel/biodiesel blend, obtaining divergent results. The reduction in temperature is a consequence of the reduction in ignition. Another reason may be the ability of nanoparticles to adsorb heat.

\section{Specific fuel consumption}

Biodiesel blends showed higher fuel consumption than base diesel due to the limited heating value. The addition of GO nano additive showed a positive effect on fuel consumption. The reduction in combustion time and ignition delay, as well as the presence of GO (which facilitated carbon oxidation), led to effective fuel combustion.

\section{Thermal efficiency of braking}

As the study showed, the presence of GO had little effect on brake heat. Typical GO concentrations for improved engine performance showed a $1.4 \%$ increase in efficiency for diesel fuel. For biodiesel, there was also an improvement in performance for the indicated GO concentration.

\section{Smoke emissions}

In [5] tests, GO there was a $22.33 \%$ reduction in smoke emissions at an optimum concentration of $40 \mathrm{ppm}$. Other concentrations had less effect on smoke. For biodiesel, adding GO had the same effect. The 40 ppm concentration gave the greatest smoke reduction compared to the 20 and 60 ppm concentrations.

The deterioration of emission reduction for higher concentration is explained by particle agglomeration and reduction of GO surface area.

\section{Emissions of nitrogen oxides}

Higher reductions in nitrogen oxide emissions were obtained for graphene nanoparticle than for graphene oxide alone. At a concentration of $40 \mathrm{ppm} \mathrm{GO}$, a reduction of
$8.5 \%$ was achieved for diesel fuel, while for biodiesel blends it amounted to $10.5 \%$ and $8.8 \%$, respectively.

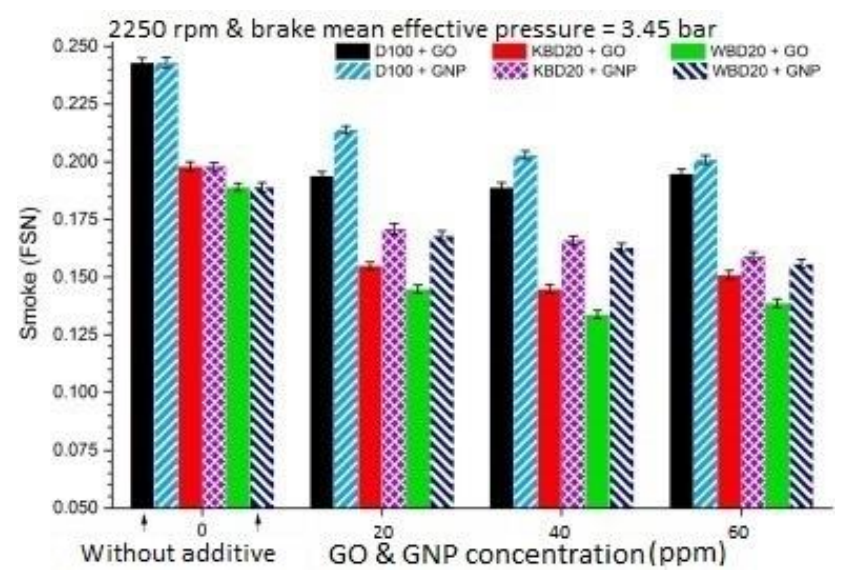

Fig. 10. Variation of smoke emission depending on the concentration GO [5]

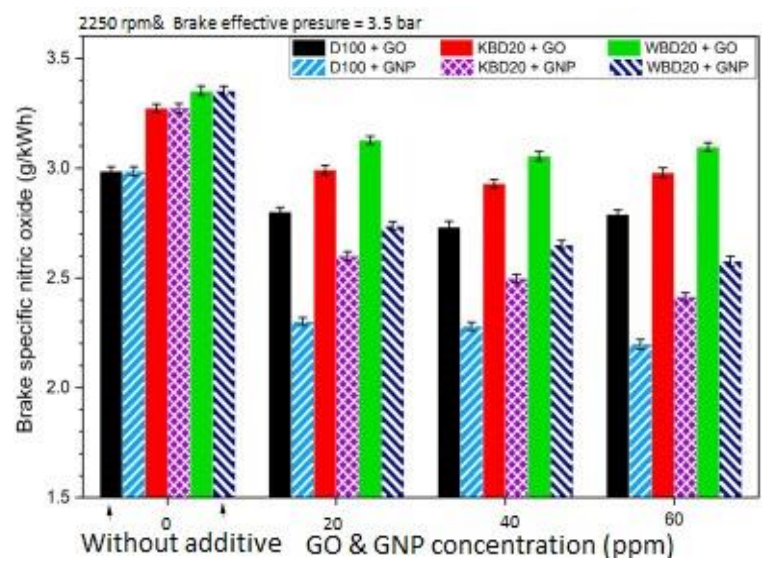

Fig. 11. Variation of $\mathrm{NO}_{\mathrm{x}}$ emission depending on the concentration GO [5]

On the other hand, graphene nanoparticle obtained better reduction for diesel, i.e. $26.4 \%$, while for biodiesel blends $-26.3 \%$ and $23.1 \%$.

\section{Hydrocarbon emissions}

The addition of GO to the fuel contributed to hydrocarbon reduction for all fuels tested (pure diesel and biodiesel blends).

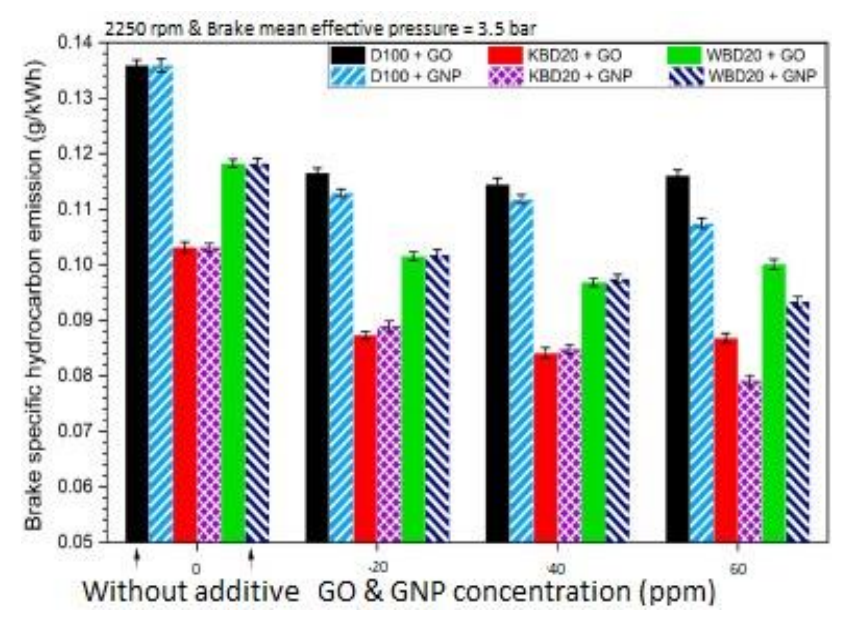

Fig. 12. Variation of $\mathrm{HC}$ emission depending on the concentration GO [5] 
This phenomenon is explained by the reduced ignition time, which prevents excessive mixing of the fuel and thus results in less unburned hydrocarbons.

\section{Carbon monoxide (CO)}

The results of [5] tests showed a reduction in $\mathrm{CO}$ emissions under the influence of GO additives in all fuels. The presence of oxygen groups in GO contributes to the oxidation of $\mathrm{CO}$ to $\mathrm{CO}_{2}$.

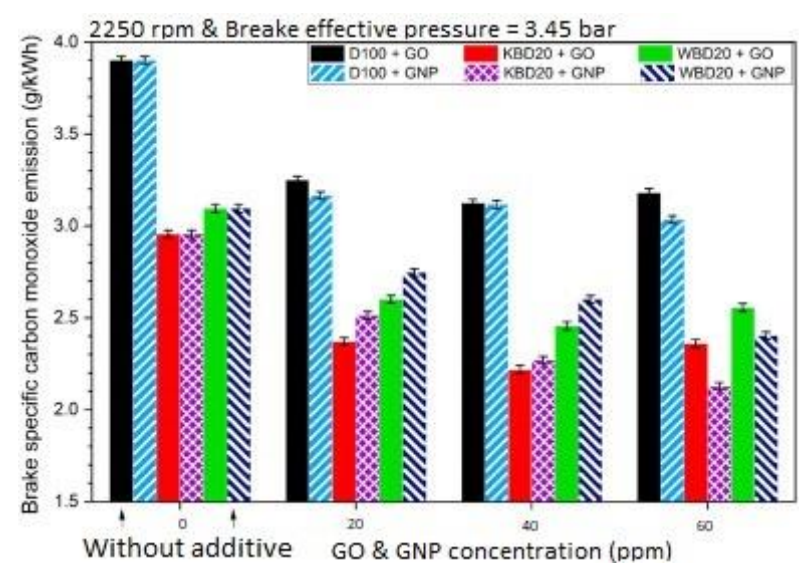

Fig. 13. Variation of CO emission depending on the concentration GO [5]

The maximum reduction reported for $40 \mathrm{ppm}$ GO in the case of diesel is $21.9 \%$ while for biodiesel blends it is $27 \%$ and $22.7 \%$. Increase in the GO concentration did not cause increase in the reduction, which is explained as in previous results by its ability to agglomerate particles.

\section{Iron oxide and zinc oxide}

Adding iron or zinc oxide nanoparticles to the fuel reduces the cohesive forces between the fuel molecules, leading to breakup into smaller droplets. This results in an increase in the momentum of the fuel jet and an increase in fuel penetration into the cylinder. Zinc oxide is noncorrosive, has antioxidant ability, high wear resistance and is inexpensive. In tests conducted by [10], $75 \%$ diesel and $25 \%$ biodiesel were mixed to form a D75NB25 blend. Ironzinc nanoxide at $200 \mathrm{ppm}$ was added to the mixture, mixed thoroughly using a magnetic stirrer to form a homogeneous mixture and ultrasonicated. The test was conducted on a two-cylinder diesel engine. A digital contact tachometer was used to measure the engine speed. The test was performed at a constant speed of 1,500 rpm with a variable brake test stand load. Physical properties like density, viscosity and calorific value were tested according to ASTM and IS standard methods. The following results were obtained [10].

\section{Specific fuel consumption during braking}

Comparing the results, iron oxide had the greatest effect on fuel consumption. However, the addition of zinc oxide also made a positive contribution to fuel consumption compared to conventional diesel. The reduction in specific fuel consumption is explained by the improved combustion rate and shorter ignition delay time. The addition of nanoparticles contributes to uniform heat distribution during heating, which improves the combustion reaction.

\section{Thermal efficiency of brakes}

As reported in [10], the thermal efficiency of brakes increases with increasing load for all fuel samples due to the increase in temperature during combustion. Adding zinc oxide and iron oxide increases the thermal efficiency, which amounts to $35.1 \%$ and $34.6 \%$ compared to pure diesel where it amounts to $30.12 \%$ and $34.23 \%$.

\section{$N O_{x}$ emissions}

Nitrogen oxide emissions were higher for the iron oxide-zinc blends at higher load, while emissions for the biodiesel-diesel blend and pure diesel were lower at higher load compared to the nano additive blends. The higher emission value is a consequence of higher density and higher oxidation capacity.

\section{Emissions of unburned hydrocarbons}

The results showed that the unburned hydrocarbon content increases with load. The mixture containing iron-zinc nanoxide had lower emissions than diesel. This phenomenon is explained by a more efficient oxidation reaction. Comparing the two nano additives, iron oxide caused lower emission.

\section{Carbon monoxide emissions}

Carbon monoxide emission observations made in [10] are variable over the engine operating load range. Carbon monoxide emissions decrease in the initial range of operation to moderate load. After the moderate value is exceeded, emissions increase. The reduction in $\mathrm{CO}$ is due to the poor area of the flame zone and the increase in $\mathrm{CO}$ is due to the reduced amount of oxygen available for combustion. Nanoparticles have the ability to catalyze combustion reactions and thus contribute to the reduction of $\mathrm{CO}$ emissions.

\section{Smoke emissions}

Observations show that iron oxide and zinc oxide nanoparticles contribute to lower smoke emissions compared to diesel. However, iron oxide particles cause the least emissions.

\section{Conclusions}

Obviously, the analysis presented by the authors does not exhaust the problem, however, the review of literature points to an interesting direction of further research on the possibilities of using nanomaterials as fuel additives. In addition, some discrepancies have been noted regarding the effect of nano-additives, for example, on the reduction of emissions of harmful gases selected pollutants. Selected groups favor this reduction and others do not, or even cause an increase in emissions, such as the use of carbon nanotubes contributes to an increase in emissions of environmentally harmful nitrogen oxides, while the presence of graphene oxide causes their reduction. It is also an interesting observation that groups like titanium oxide and graphene reduce emissions of harmful carbon monoxide by improving fuel combustion from semi-combustion to complete combustion, but in doing so cause an increase in $\mathrm{CO}_{2}$ emissions, which is in turn a greenhouse gas. The literature analysis also shows that all nanomaterials have a positive effect on the reduction of hydrocarbon emissions, which clearly indicates an improvement in combustion quality and improvement in technical parameters such as specific fuel 
consumption, cylinder temperature, exhaust temperature, ignition delay. From the review presented, it can also be seen that most of the studies were conducted on the blends of diesel and biodiesel with the nano additive, and only a few studies show the effect of adding the nanomaterial to pure diesel. Moreover, the literature is dominated by studies on the effects of nanomaterials for diesel fuels, which creates a research gap in the area of gasoline engines and sets a potential direction for further research.

\section{Nomenclature}

MWCNTs-COOH multi-walled carbon nanotubes

CNT carbon nanotubes

UHC unburned hydrocarbons

PM particulate matter

CO carbon monoxide

$\mathrm{CO}_{2}$ carbon dioxide

$\mathrm{NO}_{\mathrm{x}}$ nitrogen oxides

$\mathrm{TiO}_{2}$ titanium dioxide

$\mathrm{Ce}_{2} \mathrm{O}_{3}$ cerium oxide

$\mathrm{Al}_{2} \mathrm{O}_{3}$ aluminum oxide

\section{Bibliography}

[1] ASMatulu, R., NGUYEN, P., ASMATUlu, E. Nanotechnology safety in the automotive industry. Nanotechnology Safety. 2013, 57-72. https://doi.org/10.1016/B978-0-444-59438-9.00005-9

[2] AWAD, A.M., JALAB, R., BENAMOR, A. et al. Adsorption of organic pollutants by nanomaterial-based adsorbents: An overview. Journal of Molecular Liquids. 2020, 301, 112335. https://doi.org/10.1016/j.molliq.2019.112335

[3] BOVERHOF, D.R., BRAMANTE, C.M., BUTALA, J.H. et al. Comparative assessment of nanomaterial definitions and safety evaluation considerations. Regulatory Toxicology and Pharmacology. 2015, 73(1), 137-150.

https://doi.org/10.1016/j.yrtph.2015.06.001

[4] CAROLL, J.P., FINNAM, J.M. The use of additives and fuel blending to reduce emissions from the combustion of agricultural fuels in small scale boilers. Biosystems Engineering. 2015, 129, 127-133.

https://doi.org/10.1016/j.biosystemseng.2014.10.001

[5] CHACKO, N., JEYASEELAN, T. Comparative evaluation of graphene oxide and graphene nanoplatelets as fuel additives on the combustion and emission characteristics of a diesel engine fuelled with diesel and biodiesel blend. Fuel Processing Technology. 2020, 204, 106406. https://doi.org/10.1016/j.fuproc.2020.106406

[6] DAS, R., VECITIS, C.D., SCHULZE, A. et al. Recent advances in nanomaterials for water protection and monitoring. Chemical Society Reviews. 2017, 46, 6946-7020.

https://doi.org/10.1039/C6CS00921B

[7] FAYYAZBAKHSH, A., PIROUZFAR, V. Comprehensive overview on diesel additives to reduce emissions, enhance fuel properties and improve engine performance. Renewable and Sustainable Energy Reviews. 2017, 74, 891-901.

https://doi.org/10.1016/j.rser.2017.03.046

[8] JAYARAMAN, J., ISLAMLASKA, I., DEY, K. et al. Investigation on titanium oxide nano particles as additives for operating biodiesel fuelled engine. Materials Today. 2021, 44(5), 3525-3529.

https://doi.org/10.1016/j.matpr.2020.09.291

[9] KEGL, T., KRALJ, A.K., KEGL, B. et al. Nanomaterials as fuel additives in diesel engines: A review of current state, opportunities and challenges. Progress in Energy and Combustion Science. 2021, 83, 100897. https://doi.org/10.1016/j.pecs.2020.100897

[10] KHOND, V.W., RAMBHAD, K., RAMBHAD, K. New diesel-neem biodiesel blend (D75NB25) containing nano iron oxide, silicon dioxide and zinc oxide for diesel engine: An experimental investigation Materials Today. 2021, 47(11), 2701-2708.

https://doi.org/10.1016/j.matpr.2021.03.004
[11] LOKESH, N., SHAAFI, T. Enhancement of diesel fuel properties: Impact of cerium oxide nano additives on diesel engine performance and emissions. Materials Today.

https://www.sciencedirect.com/science/article/pii/S2214785 320375465

[12] MANOJ, P., KALYAN, B., JAYARAMAN, B. et al. Experimental assessment of alumina nano additives on the performance of C.I. engine fuelled with a high-performance fuel blend. Materials Today. 2021, 44(5), 3544-3549. https://doi.org/10.1016/j.matpr.2020.09.373

[13] FOLTYNOWICZ, Z., CZAJKA, B., MARANDA, A. et al. Aspects of nanomaterials for civil and military applications. Part 2. The use of and concerns arising from infiltration of the natural environment. Materiaty Wysokoenergetyczne/ High Energy Materials. 2017, 9, 18-39. https://doi.org/10.22211/matwys/0158 ISSN 2083-0165

[14] GUNDOSHMIAN, T.M., HEIDARI-MALENI, A., JAHANBAKHSHI, A. Evaluation of performance and emission characteristics of a CI engine using functional multi-walled carbon nanotubes (MWCNTs-COOH) additives in biodiesel-diesel blends. Fuel. 2021, 287, 119525. https://doi.org/10.1016/j.fuel.2020.119525

[15] MUVVA, R., SHAAFI, T., ARUNKUMAR, M. Experimental investigation by utilizing nano alumina with waste cooking oil biodiesel fuel in CI engine. Materials Today. https://www.sciencedirect.com/science/article/pii/S2214785 320377865

[16] SINGH, S., KAPOOR, D., KHASNABIS, S. et al. Mechanism and kinetics of adsorption and removal of heavy metals from wastewater using nanomaterials. Environmental Chemistry Letters. 2021, 1-31. https://doi.org/10.1007/s10311-021-01196-w

[17] SOUDAGAR, M.E.M., NIK-GHAZALI, N.N., KALAM, M.A. et al. The effect of nano-additives in diesel-biodiesel fuel blends: A comprehensive review on stability, engine performance and emission characteristics. Energy Conversion and Management. 2018, 178, 146-177. https://doi.org/10.1016/j.enconman.2018.10.019

[18] SUNIL, S., CHANDRA, B.S. Studies on titanium oxide nanoparticles as fuel additive for improving performance and combustion parameters of CI engine fueled with biodiesel blends. Materials Today. 2021, 44(1), 489-499. https://doi.org/10.1016/j.matpr.2020.10.200

[19] WANG, L., SHI, C., WANG, L. et al. Rational design, synthesis, adsorption principles and applications of metal oxide adsorbents: a review. Nanoscale. 2020, 12, 47904815. https://doi.org/10.1039/C9NR09274A

[20] WANG, R., LI, X., NIE, Z. et al. Metal/metal oxide nanoparticles-composited porous carbon for high-performance 
supercapacitors. Journal of Energy Storage. 2021, 38, 102479. https://doi.org/10.1016/j.est.2021.102479

[21] YU, G., LU, Y., GUO, J. et al. Carbon nanotubes, graphene, and their derivatives for heavy metal removal. Advanced. 2018, 1, 56-78. https://doi.org/10.1007/s42114-017-0004-3

[22] ZHANG, J.J., HAN, L., WANG, J. et al. Graphene-based materials for adsorptive removal of pollutants from water and underlying interaction mechanism. Advances in Colloid and Interface Science. 2021, 289, 102360. https://doi.org/10.1016/j.cis.2021.102360

\footnotetext{
Agata Jaroń, MEng. - Faculty of New Technologies and Chemistry, Military University of Technology.

e-mail: a.jaron04@gmail.com
}

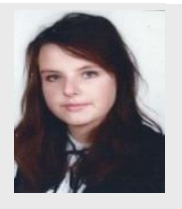

Anna Borucka, DSc., DEng. - Faculty of Safety, Logistics and Management, Military University of Technology.

e-mail: anna.borucka@wat.edu.pl
[23] ZHANG, Z., LU, Y., WANG, Y. et al. Comparative study of using multi-wall carbon nanotube and two different sizes of cerium oxide nanopowders as fuel additives under various diesel engine conditions. Fuel. 2019, 256, 115904.

https://doi.org/10.1016/j.fuel.2019.115904

[24] OUYANG, Y., CONG, L.M., CHEN, L. et al. Raman study on single-walled carbon nanotubes and multi-walled carbon nanotubes with different laser excitation energies. Physica E: Law-dimensional System and Nanostructures. 2008, 9, 2386-2389. https://doi.org/10.1016/j.physe.2007.11.008

Grzegorz Sobecki, MEng. - School Battalion, Military University of Technology.

e-mail: grzegorz.sobecki@wat.edu.pl
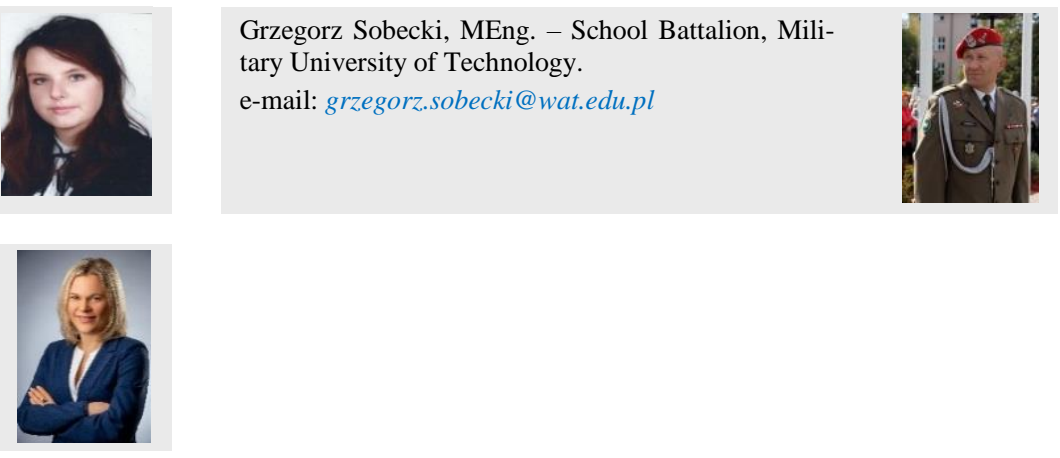